\title{
SÍNTESE, IDENTIFICAÇÃO E QUANTIFICAÇÃO DE PARABENOS EM EDULCORANTES: UMA ABORDAGEM CONTEXTUALIZADA PARA O ENSINO DE QUÍMICA
}

\author{
T. A. CORRÊA ${ }^{1}$, R. M.A. RODRIGUES ${ }^{2}$, L. DE P. MELO ${ }^{3}$, G. H. G. $\operatorname{COSTA}^{4}$ \\ Universidade do Estado de Minas Gerais \\ ORCID ID: https://orcid.org/0000-0001-9936-1479 1 \\ tais.correa@uemg.br ${ }^{1}$
}

Submetido 20/04/2020 - Aceito 11/08/2020

DOI: $10.15628 /$ holos.2020.9945

\section{RESUMO}

Tendo em vista a interdisciplinaridade do Curso Superior de Tecnologia em Alimentos, dar significado aos diferentes conteúdos que compõem o currículo é de extrema relevância para profissionais críticos que atuarão ativamente na sociedade. Neste sentido, aulas laboratoriais contextualizadas podem contribuir para a efetivação da aprendizagem, desenvolvendo no discente o espírito investigativo além de aproximar o conteúdo à vivência do aluno. Assim, propõe-se nesse trabalho um
\end{abstract}

conjunto de aulas experimentais para as disciplinas de Química, contextualizada com a temática conservação de alimentos, que demonstre as etapas do desenvolvimento de um conservante sintético (metilparabeno), sua identificação e quantificação em edulcorantes artificiais, além de avaliar a estratégia junto aos estudantes.

PALAVRAS-CHAVE: Atividades Experimentais, Tecnologia em Alimentos, Aprendizagem, Conservantes Artificiais

\section{SYNTHESIS, IDENTIFICATION AND QUANTIFICATION OF PARABENS IN SWEETENERS: A CONTEXTUALIZED APPROACH FOR TEACHING CHEMISTRY}

\begin{abstract}
In view of the interdisciplinarity of undergraduate in Food Technology, to give meaning to the subjects of curriculum is extremely relevant to teaches students for be a critical professional in society. Therefore, contextualized laboratory classes can contribute to the learning process, developing in the student the scientific curiosity, bringing the subjects closer to the student experience. Thus, this work to propose a set of experimental classes for the
\end{abstract}

chemistry subject, contextualized with the thematic preservatives in food, which demonstrates the steps of synthetic preservative (methylparaben) production, identification and quantification of methylparaben in artificial sweeteners, in addition to evaluate the approach with the students.

KEYWORDS: : Experimental Activities, Food Technology, apprenticeship, Artificial Preservatives. 


\section{INTRODUÇÃO}

A química é uma área da ciência que compõe a grade curricular da maioria dos cursos das Ciências Exatas e da Terra, Biológicas, da Saúde, entre outros. Geralmente está disposta no currículo escolar como: química geral, química analítica, química inorgânica, química orgânica e físico-química. Entretanto, observa-se que muitos conteúdos são ministrados de forma fragmentada, enfatizando sua memorização e reprodução, descontextualizados do cotidiano dos discentes, implicando numa aprendizagem, muitas vezes, pouco significativa.

Neste âmbito, a experimentação pode fomentar variadas e importantes contribuições no ensino e aprendizagem de química, como: favorecer a criatividade, aprimorar a capacidade de observação e análise de dados/formas de representação (gráficos, tabelas, símbolos, expressões, etc); propor hipóteses para os fenômenos e compreender as relações entre ciência, tecnologia e sociedade (Oliveira, 2010). No entanto, observa-se que as aulas laboratoriais implementas no ensino superior, em sua maioria, seguem o modelo descritivo-reprodutivo e muitas vezes não atendem as expectativas de promover um ensino envolvido com a construção do conhecimento, tornando-se muito técnicas e uma forma de desenvolvimento de habilidades e manipulação de aparatos laboratoriais. Sato (2011) complementa:

[...] Ocorre uma distorção da relação teoria e prática. Posto que os alunos acabem não compreendendo como ocorre o desenvolvimento do pensamento científico, uma vez que não formulam hipóteses, não buscam maneiras de solucionar questões, não analisam livremente os dados obtidos, estes, apenas, seguem um roteiro, preenchendo lacunas que lhes são propostas. Acabam sendo levados a crer que a prática está subordinada a teoria. Sendo a atividade pratica experimental, nesta visão, nada mais que uma forma de confirmar a teoria (Sato, 2011, p. 13).

Assim, como uma possível forma de diminuir a distância entre uma aula laboratorial e uma aula prática construtivista, é necessário que se proponha um híbrido entre as mesmas, envolvendo diferentes saberes (conceitual, procedimental, atitudinal), objetivando um ensino mais humanista e que instigue o espirito investigativo e criativo dos discentes, favorecendo o desenvolvimento de competências para sua formação profissional e o exercício de seu senso perscrutador.

Neste contexto, deve-se destacar os cursos na área de Ciências de Alimentos principalmente os de caráter tecnológico, que são interdisciplinares e com expressivo conteúdo aplicado em seus projetos pedagógicos. Entre esses, o curso de Tecnologia em Alimentos apresenta um volume significativo de conteúdos de química associados a carga horária prática como, por exemplo, na disciplina de Conservação de Alimentos. Essa é fundamental para a formação do aluno no campo dos alimentos, pois os conceitos estudados serão aplicados de forma constante em sua atividade profissional, sendo a aula pratica uma importante e fundamental ferramenta no processo de ensino-aprendizagem.

Cabe mencionar que as indústrias alimentícias dispõem de um vasto número de técnicas e substâncias químicas que são empregadas com o objetivo de retardar ou impedir alterações provocadas por micro-organismos ou enzimas. Nessa classe de compostos, os ésteres do ácido $p$ hidroxibenzóico, também conhecidos como parabenos apresentam amplo espectro de atividade 
antimicrobiana, sendo o metilparabeno o conservante frequentemente utilizado em condimentos, sucos, edulcorantes, dentre outros produtos alimentícios, devido ao seu baixo custo e aceitação regulatória (Petruci, Cardoso \& Pereira, 2011).

Entretanto, diferentes estudos revelam que o uso desses agentes conservantes tem como inconvenientes efeitos adversos à saúde como, por exemplo, reações de hipersensibilidade, acidose metabólica e desregulação hormonal (Bila \& Dezotti, 2007; Witorsch \& Thomas, 2010; Hope \& Pais, 2017).

O aprendizado da quantificação do metilparabeno em produtos alimentícios é importante para o discente de graduação em Tecnologia em Alimentos, principalmente no que tange o controle de qualidade do produto e a proteção ao consumidor. A legislação brasileira controla e determina sua concentração máxima permitida, estabelecendo o limite de $300 \mathrm{mg}$. $\mathrm{kg}^{-1} \mathrm{em}$ bebidas não alcoólicas gaseificadas e não gaseificadas (ANVISA, 2007). Juntamente a quantificação, a preparação (síntese e purificação) dessa classe de compostos também se torna enriquecedora para construção do conhecimento, ampliando a visão do estudante sobre todo o processo.

A síntese de parabenos pode ser realizada através de uma reação de esterificação, entre o grupo carboxílico do ácido $p$-hidroxibenzóico com álcoois de cadeia curta, na presença de catalisador ácido (Fernandes et al., 2003), e as reações acompanhadas por cromatografia em camada delgada (CCD), empregando combinações entre as fases móveis (eluentes) e estacionárias. A CCD é considerada uma técnica muito versátil pela facilidade em efetuar a separação, identificação e quantificação dos compostos químicos de uma mistura.

Após o procedimento sintético, a purificação dos parabenos pode ser efetuada por precipitação ou cristalização, levando a formação de sólidos/cristais brancos, e sua obtenção confirmada através do ponto de fusão, em comparação com dados da literatura. Dentre as diversas técnicas analíticas empregadas para a determinação de parabenos, dispõem-se da espectrofotometria de absorção molecular na região do visível e ultravioleta (UV-Vis). Os três métodos apontados são considerados de fácil aplicação e de baixo custo para a obtenção, caracterização e quantificação de compostos orgânicos e inorgânicos, respectivamente, tornandose processos interessantes e viáveis para diferentes indústrias como, por exemplo, a indústria de alimentos.

Diante do apresentado, o tema "Preparação e Avaliação de Parabenos como conservantes sintéticos" se mostra como uma proposta interessante para a contextualização do ensino de Química dentro do curso de Tecnologia em Alimentos, pois permite a construção de aulas experimentais dinâmicas, fundamentadas nas informações adquiridas em aulas teóricas, cuja interpretação levará a elaboração de conceitos e desenvolvimento de competências para sua formação profissional.

O presente trabalho propôs à elaboração de um conjunto de aulas experimentais como ferramenta didática contextualizada para o ensino de Química fazendo uma correlação entre as etapas do desenvolvimento de uma molécula bioativa, como a síntese, purificação e identificação (CCD), além da aplicação de um método simples e rápido empregado para a quantificação por espectrofotometria no UV-Vis para a análise de metilparabeno em produtos alimentícios, como edulcorantes sintéticos. 


\section{METODOLOGIA}

A pesquisa foi dividida em duas etapas: I) Padronização da metodologia para a preparação e quantificação de metilparabeno em edulcorantes; II) Desenvolvimento do material didático e aplicação das aulas experimentais para alunos do curso de Tecnologia em Alimentos. A etapa I foi desenvolvida na Universidade do Estado de Minas Gerais (UEMG), nas unidades de Frutal e Ubá; enquanto a etapa II foi aplicada na UEMG, unidade Frutal.

\subsection{Padronização da metodologia para a preparação e quantificação de Parabenos}

Para elaboração do material didático, as etapas de síntese, purificação, identificação e quantificação do metilparabeno (MP) em amostras de edulcorantes foram previamente avaliadas em laboratório, estabelecendo as melhores condições para sua reprodução nas aulas laboratoriais propostas.

Todos os reagentes utilizados na síntese foram obtidos comercialmente com pureza adequada para a realização do processo. As amostras de edulcorantes foram adquiridas no comercio local do município de Frutal-MG, considerando no processo de amostragem a data de validade, o lote, o tipo de adoçante assim como as informações contidas nos rótulos dos produtos.

O ponto de fusão foi medido no aparelho digital de ponto de fusão Microquímica, modelo MQAF. Para a análise da pureza dos compostos, andamento das reações e identificação do MP em amostras de edulcorante foi empregada a cromatografia em camada delgada (CCD) em sílica gel 60G suportada em lâminas de vidro ou placas de alumínio de Kiesegel (cromatofolhas 60F 254 ). A quantificação do metilparabeno foi realizada em espectrofotômetro de absorção no UV-Vis marca BEL Photonichs, modelo UV-M51.

\subsubsection{Procedimento geral para a síntese do metilparabeno}

A síntese do metilparabeno, em escala laboratorial, seguiu a metodologia proposta por Fernandes et al (2013), com algumas adaptações. Em um balão de fundo chato, uma mistura de 0,304g (20 mmol) de ácido $p$-hidróxibenzoico, $15 \mathrm{~mL}$ de metanol e 0,5 $\mathrm{mL}$ de ácido sulfúrico concentrado (catalisador), foi mantida sob agitação magnética e refluxo por $40 \mathrm{~min}$. A reação foi acompanhada por meio de CCD (eluente: clorofórmio/metanol - 9,5:0,5 v/v) e revelada por vapor de iodo. Para determinação do fator de retenção $(R f)$ foi empregado a razão entre a distância percorrida pela substância em questão (ds) e a distância percorrida pela fase móvel $(\mathrm{dm})(R f=$ $\mathrm{ds} / \mathrm{dm}$ ), e as medidas ( $\mathrm{ds}$ e $\mathrm{dm}$ ) realizadas a partir da linha de base até o centro da mancha dos produtos em estudos. Ao final, a reação foi neutralizada com solução saturada de carbonato de sódio (até pH 8-9) e o sólido branco formado foi filtrado a vácuo e lavado com água destilada.

\subsubsection{Procedimento geral para purificação e caracterização do metilparabeno}

Para a purificação por cristalização, inicialmente a solubilidade do metilparabeno foi testada, a frio (temperatura ambiente) e a quente (aquecimento), empregando os solventes: água e etanol. Em tubos de ensaio foram adicionados uma pequena porção da amostra (ponta de espátula) e $3 \mathrm{~mL}$ do solvente a ser testado. Em seguida os tubos foram aquecidos até próximo a ebulição, observando a possível solubilização do MP em cada solução. Definido o 
solvente adequado ao processo de dissolução do MP a quente, em um erlenmeyer foi transferido $20 \mathrm{mg}$ do MP e o menor volume possível do solvente avaliado, aquecendo-se a mistura até completa dissolução do sólido. Para a obtenção dos cristais, a solução foi resfriada à temperatura ambiente e deixada em repouso.

Para a determinação da faixa e ponto de fusão, um cristal foi disposto entre duas lâminas de vidro, sobre a placa de aquecimento do aparelho, que foi aquecida até atingir $10^{\circ} \mathrm{C}$ abaixo da temperatura do ponto de fusão esperado. Em seguida a temperatura foi aumentada a uma taxa de $0,5{ }^{\circ} \mathrm{C}$ por minuto até a completa fusão do composto. A temperatura inicial (primeira gota de líquido a se formar) e final (últimos cristais de sólido desaparecem) foram registradas.

\subsubsection{Procedimento geral para identificação da presença de metilparabeno nas amostras de interesse}

A identificação da presença do metilparabeno nas amostras de edulcorantes foi realizada através da Cromatografia em Camada Delgada (CCD), empregando-se como fase fixa de sílica gel 60G suportada em lâminas de vidro ou placas de alumínio no tamanho de $10 \times 4$ $\mathrm{cm}^{2} \mathrm{e}$, como fase móvel, mistura dos solventes, clorofórmio e metanol. Após a eluição, as placas foram submetidas à revelação por vapor de iodo e os fatores de retenção, $R f s$, dos produtos eluídos foram observados, analisados e comparados a padrões e dados dispostos na literatura.

\subsubsection{Procedimento geral para quantificação de metilparabeno nas amostras de edulcorantes}

A quantificação dos parabenos foi realizada através da leitura de absorbância das amostras dos edulcorantes artificiais em um espectrofotômetro de absorção no UV-Vis. Para preparação da curva analítica foi selecionado o comprimento de onda máximo de absorção dos parabenos $(\lambda=254 \mathrm{~nm}$ ) e diluição das amostras em cubeta de quartzo de $1,0 \mathrm{~cm}$. As análises foram realizadas empregando $0,150 \mathrm{~g}$ das amostras de adoçantes, tratadas com $20 \mathrm{~mL}$ de solução aquosa de ácido acético a $1 \%$ e metanol (25:75, v/v), seguido de aquecimento em banho-maria, centrifugação e filtração para separação do sobrenadante (OliveiraL \& Lima, 2011).

A curva analítica foi construída utilizando-se um padrão de metilparabeno a qual contemplou os valores máximos de concentração permitidos pela ANVISA. A curva foi construída a partir da diluição de uma solução estoque de concentração $0,316 \mathrm{mg} \cdot \mathrm{mL}^{-1}$. A leitura do branco de referência foi realizada para cada concentração visando diminuir os erros analíticos oriundos da absorção da cubeta e do solvente usado na diluição das amostras (metanol, $\lambda_{\text {máximo }}=205 \mathrm{~nm}$ ). Todas as medidas de absorbância foram realizadas em triplicatas $(n=3)$, considerando-se o desvio padrão das medidas e o coeficiente de variação (CV) para todas as concentrações.

\subsection{Elaboração do material didático e aplicação das aulas experimentais}

O material didático foi estruturado em quatro partes, correlacionando os conteúdos de química com a temática "Conservantes Alimentícios" através da preparação, identificação e quantificação de um conservante químico (metilparabeno) em edulcorante comercial, de forma 
que possam ser incluídos nos planos de aula das diferentes disciplinas. Foi realizada uma pesquisa exploratória, sobre a temática para contextualização dos conteúdos programáticos de química inseridos no currículo do Curso de Tecnologia em Alimentos e montagem dos roteiros experimentais, contemplando: introdução ao tema, materiais necessários, trajetória investigativa, interpretação dos resultados e Sistema de Tratamento de Resíduos.

Em seguida foi planejado e executado um minicurso de extensão com as aulas experimentais contextualizadas para os alunos matriculados nos períodos finais do Curso Superior em Tecnologia em Alimentos da UEMG-Frutal, observando a concepção construtivista de aprendizagem. Por final, a atividade proposta foi avaliada de forma qualitativa sobre sua contribuição para o processo ensino-aprendizagem.

\section{RESULTADOS E DISCUSSÃO}

O material didático elaborado contemplou três áreas de concentração da Química, sendo elas: Química Geral, Química Orgânica e Química Analítica, e composto por quatro atividades experimentais: 1) Obtenção do metilparabeno; 2) Purificação por cristalização; 3) Identificação do MP por Cromatografia em CCD em amostras de edulcorantes sintéticos; 4) Quantificação do MP por espectrofotometria de absorção no UV-Vis.

O minicurso foi realizado na I Semana Acadêmica do Curso Superior em Tecnologia em Alimentos, nas dependências da UEMG- Frutal, entre os dias 17 e 20 de outubro de 2018, com carga horária total de 8 horas. A atividade contou com a participação de 12 discentes que foram divididos em 3 grupos de 4 componentes, onde cada equipe trabalhou desde a síntese do metilparabeno até a sua quantificação na amostra de edulcorante. Para a realização das aulas experimentais foi necessário o uso de dois laboratórios, sendo ministrada 2 aulas por dia, e a utilização de três computadores para o tratamento dos dados coletados.

A primeira atividade experimental "Obtenção do metilparabeno" contemplou diferentes conceitos químicos como: estequiometria (equações químicas, massa molecular, mol, reagente limitante e rendimento), cinética química (catálise homogênea), funções orgânicas e mecanismo de reação além de trabalharem medidas de volume e massa, métodos de aquecimento e separação de mistura (filtração), trabalhando-os de forma integrada.

Os alunos participaram da montagem do aparato para a preparação do MP (Figura 1A) que abordou como estratégia sintética uma reação de substituição nucleofílica acíclica entre o grupo carboxílico (-COOH) do ácido $p$-hidroxibenzóico com um álcool de cadeia curta (metanol: $\mathrm{CH}_{3} \mathrm{OH}$ ), na presença de catalisador ácido $\left(\mathrm{H}_{2} \mathrm{SO}_{4}\right)$, também conhecida como esterificação de Fischer. $\mathrm{A}$ reação foi acompanhada por CCD, através da comparação entre os fatores de retenção do material de partida, um misto entre o material de partida e a reação, e somente a reação, observando-se a formação do metilparabeno que apresentou um $\operatorname{Rf}$ superior $(0,57)$ ao do ácido $p$-hidroxibenzoico $(0,14)$, nas condições estabelecidas (Figura 1B). O produto de interesse foi obtido após filtração, na forma de sólido branco (Figura 1C), em rendimentos que variaram entre 43 a 64\%. 

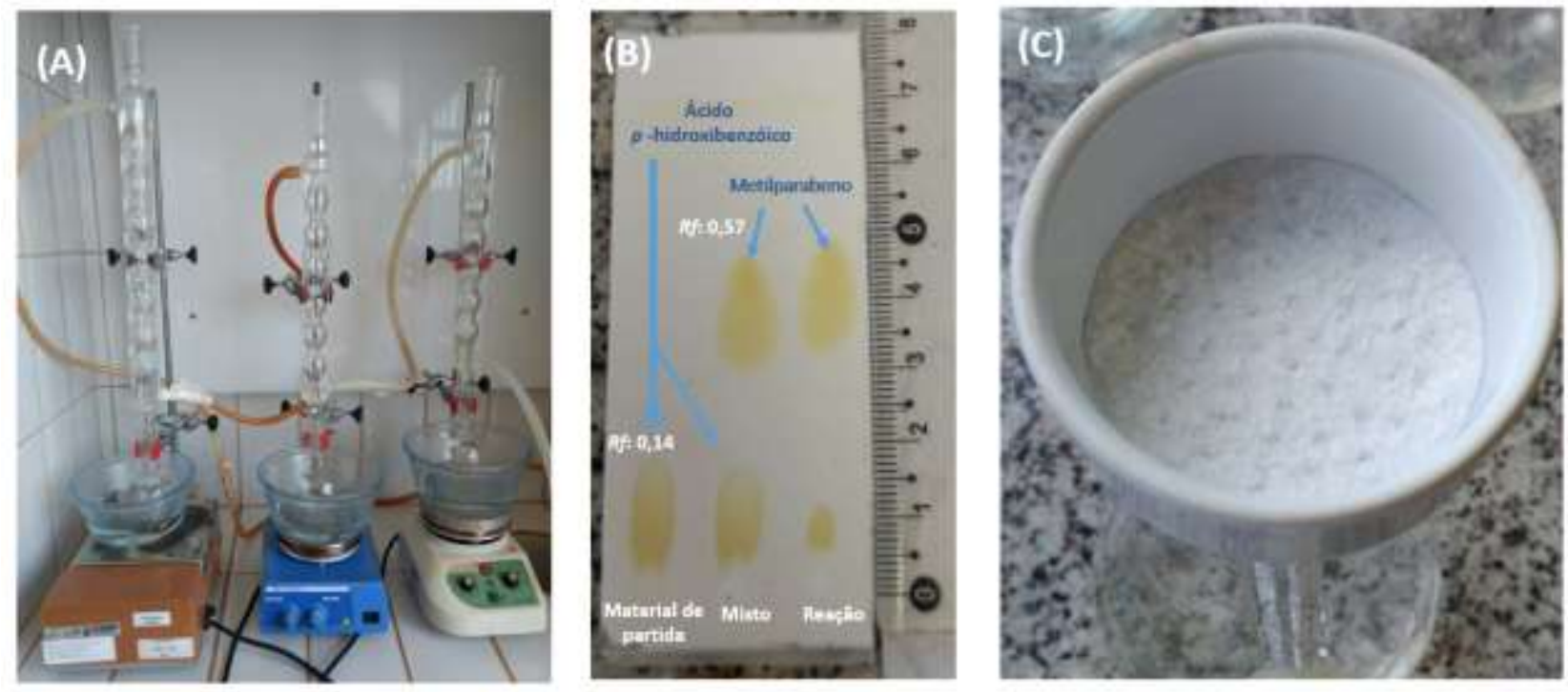

Figura 1: (A) Montagem do aparato laboratorial para a síntese do MP; (B) Placa cromatográfica - eluente: clorofórmio (9,5 mL): metanol (0,5 mL) e revelador: vapor de iodo; (C) Sólido filtrado.

A segunda aula experimental "Purificação por cristalização" deu continuidade ao processo de obtenção do metilparabeno. Discutiu-se de forma aplicada os conteúdos de solubilidade e polaridade de moléculas orgânicas, ligações intermoleculares, através de um método de purificação de sólidos (cristalização) e caracterização por meio do ponto de fusão.

De acordo com os solventes testados, o etanol foi efetivo na solubilização do MP a temperatura ambiente e após aquecimento, já a água solubilizou a amostra apenas após aquecimento, sendo o último escolhido para realização do processo. $O$ metilparabeno foi obtido como pequenos cristais incolores ou na forma de pó branco após filtração a vácuo. A pureza do MP foi verificada por CCD em comparação com o padrão analítico e sua obtenção sugerida através da observação da faixa e ponto de fusão, comparado com dados da literatura, obtendo o valor da faixa de fusão $124-128^{\circ} \mathrm{C}$ (início e termino, respectivamente), e o ponto de fusão $126^{\circ} \mathrm{C}$ calculado através da média entre o ponto de fusão inicial e final (Fernandes et al., 2013).

A terceira aula experimental "Identificação do MP por Cromatografia em CCD em amostras de edulcorantes sintéticos" abordou conceitos de um importante método físico-químico de separação rápida e análise qualitativa, fundamentado na migração diferencial entres os solutos presentes em uma mistura, a fase estacionária e a fase móvel, aplicado em experimentos de macro e microescala.

Foram selecionadas 4 amostras de adoçante sintético a base de Aspartame, cujos três rótulos informavam a presença de metilparabeno como um dos conservantes utilizados. Os alunos analisaram os rótulos, identificaram os diferentes aditivos químicos presentes nas formulações e estudaram de forma mais detalhada os princípios básicos da Cromatografia em Camada Delgada (aplicação da amostra na placa, escolha da fase móvel, a separação da mistura por processos de equilíbrio e métodos de revelação) para identificação da presença ou não de MP nas amostras selecionadas.

Diante dos resultados obtidos os estudantes observaram que a mistura clorofórmio e metanol na proporção 9,5:0,5 (v/v) e o revelador iodo foram eficientes para a separação e 
visualização do composto de interesse, respectivamente. Das quatro amostras avaliadas, três edulconates (amostras 1, 2 e 4) apresentaram MP em suas formulações, por comparação com o padrão de referência, e um edulcorante (amostra 3) não continha este composto como conservante (Figura 2), estando os resultados de acordo com o descrito pelos fabricantes.

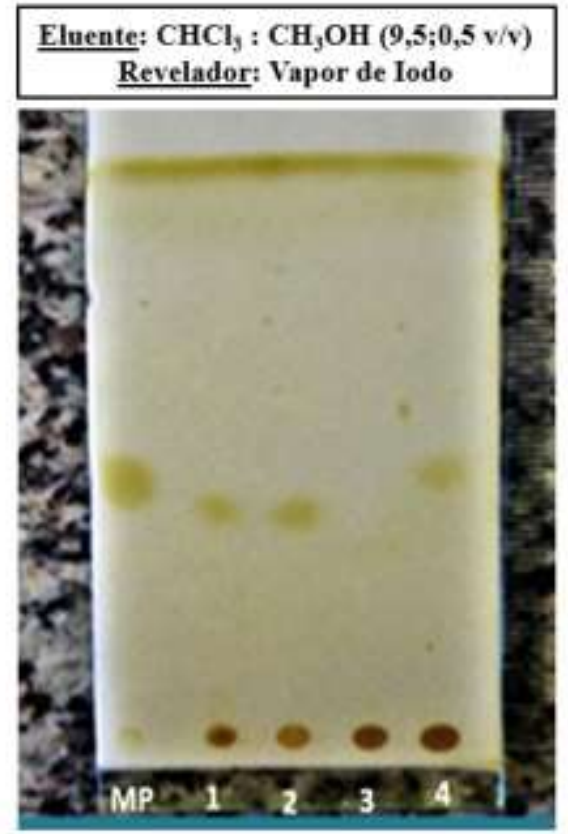

Figura 2: Placa cromatográfica ilustrando a presença do composto metilparabeno (MP) em amostras de aspartame (1 a 4).

Na quarta aula experimental “Quantificação do MP por espectrofotometria de absorção no UV-Vis", foi abordado os princípios básicos da espectrofotometria no UV-Vis, técnica amplamente empregada para a determinação de compostos orgânicos em diversas áreas. O experimento consistiu em aplicar a absorção da radiação no UV-Vis (comprimento de onda selecionado $254 \mathrm{~nm}$ ) para quantificar o metilparabeno nas amostras de interesse. Para isso o docente, juntamente com os alunos, construíram uma curva analítica variando as concentrações de metilparabeno (intervalo linear de 0,0032 a 0,32 g. $\mathrm{mL}^{-1}$ ) (Figura 3). Cada equipe trabalhou com uma amostra que apresentou resultado positivo do experimento anterior, realizando o processo de abertura, quantificação e tratamento dos dados. 


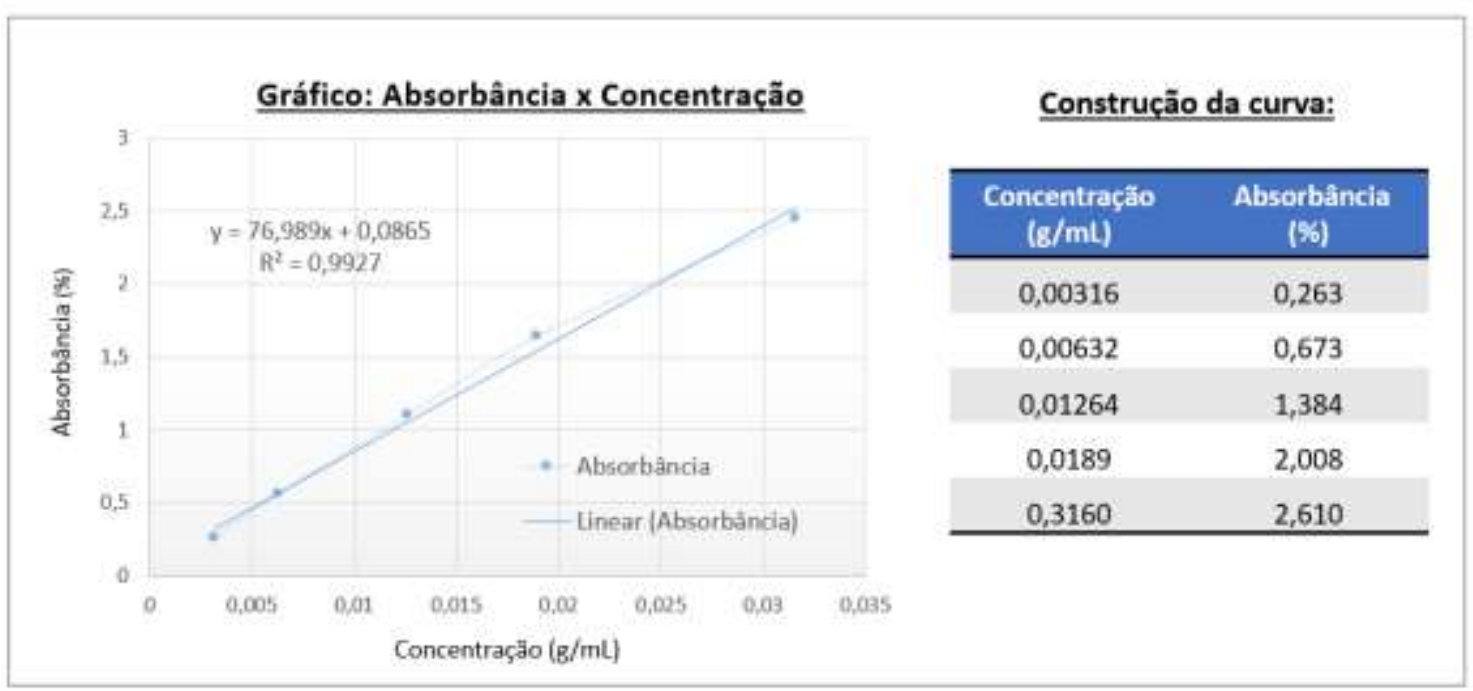

Figura 3: Curva analítica obtida com o padrão metilparabeno: Solução Estoque de 15,8 mg para $50 \mathrm{~mL}$ de metanol (Concentração de $0,316 \mathrm{mg} \cdot \mathrm{mL}^{-1}$ ).

As concentrações do conservante nas amostras de edulcorantes foram determinadas empregando a equação da reta obtida através da construção da curva analítica de metilparabeno ( $y=76,989 x+0,0865$, onde y corresponde a absorbância do composto e $x$ é a concentração em $\mathrm{mg} \cdot \mathrm{mL}^{-1}$ ), como disposto na Figura 4 . O método analítico proposto apresentou linearidade adequada com coeficiente de determinação $\left(R^{2}\right)$ igual 0,9927. Segundo os resultados obtidos as concentrações determinadas se encontram dentro do valor máximo permitido pela ANVISA (300 mg. $\left.\mathrm{Kg}^{-1}\right)$, a qual variou de 166 a $273 \mathrm{mg} . \mathrm{Kg}^{-1}$.

Além da aplicação da técnica de espectrofotometria no UV-Vis, foi discutido com os estudantes a presença de possíveis interferentes nas análises realizadas, como o ácido benzoico e o benzoato de sódio, no qual as avaliações necessitariam de uma melhor investigação, já que segundo a literatura os compostos absorvem em comprimentos de onda muito próximos do metilparabeno.

Observou-se que durante a realização das atividades experimentais alguns alunos apresentaram dificuldades com a aplicação de conceitos específicos como, por exemplo, estequiometria, cálculo de concentração e mecanismos de reações orgânicas, sendo uma forma de contribuir com a aprendizagem de conteúdos previamente abordados e diagnosticar deficiências.

Lazzari et al (2015) e Oliveira (2010) acrescentam que as aulas expositivas e experimentais são processos dinâmicos de trocas de informações onde o educando tem contato direto com o objeto de aprendizado, e complementares, pois a aplicação de apenas uma das modalidades pode desfavorecer a assimilação dos conteúdos, já que a realização do experimento necessita de um embasamento teórico para dar compreensão aos conceitos estudados.

Nas quatro aulas experimentais trabalhadas os alunos não seguiram apenas o roteiro proposto, mas estavam ativamente envolvidos em situações de questionamento, organização do pensamento, construção e socialização de argumentos associados ao problema apresentado, caracterizando-se assim como modalidade didática de caráter investigativo, além de ter 
fomentado a familiarização com as técnicas básicas dos laboratórios de química e equipamentos, cumprindo sua função pedagógica.

Tal observação vai de encontro com a metodologia construtivista sugerida por Freire (1996), também descrita por Leão (2014), que tem como teoria base a aprendizagem significativa. De acordo com os autores, quando o aluno é instigado a curiosidade, ele é também levado a encontrar respostas para os questionamentos, auxiliando o processo da construção do conhecimento. Nesta concepção cabe ao professor às questões pertinentes à didática do objeto a ser estudado, o papel de organizar as situações de aprendizagens e intervenções pedagógicas que auxiliem os estudantes com suas próprias construções.

Ao trabalhar o tema "Parabenos como conservante químico" foi possível relacionar os conteúdos estudados com as atividades práticas de forma contextualizada, saindo das perspectivas empiristas no qual os experimentos são concebidos como manipulação de variáveis e dedução de teorias, tornando-se uma estratégia eficiente para a abordagem de problemas reais e o estímulo para a investigação, aproximando a ciência da sociedade.

A contextualização também favoreceu a interdisciplinaridade, através da possibilidade de integração dos conhecimentos químicos com outras disciplinas que compõe seu currículo como, por exemplo, Conservação de Alimentos e Legislação de Alimentos, promovendo um diálogo entre as áreas e diminuindo a fronteira epistemológica.

Santos \& Nagashim (2017) complementam que aulas experimentais podem enriquecer o planejamento e a prática de ensino e assim criar pontos de articulação com temas e conteúdos, contribuindo no processo de aprendizagem. Entretanto Luca e colaboradores (2018) pontuam que se deve evitar a realização do experimento pelo experimento, distante das implicações sociais, sendo imprescindível a construção de argumentos que respondam aos questionamentos e discussão em grupo, colaborando para a autonomia, apropriação e socialização do conhecimento.

\section{CONSIDERAÇÕES FINAIS}

O presente trabalho apresentou a experimentação como uma importante ferramenta pedagógica, trazendo algumas contribuições sobre a relação entre a parte teórica e as práticas experimentais no ensino de química, dentro do contexto do Curso de Tecnologia em Alimentos. 0 planejamento das aulas experimentais abordando as diferentes etapas de preparação, identificação e quantificação de uma molécula bioativa, de forma contextualizada, proporcionou uma aprendizagem mais significativa, tirando os estudantes da condição passiva tanto na execução quanto na discussão dos resultados, além de torná-las mais dinâmicas e interessantes, abrindo a possibilidade de diálogo entre os discentes e professores.

\section{AGRADECIMENTOS}

Programa Institucional de Apoio à Pesquisa - PAPq /UEMG 


\section{REFERÊNCIAS}

Agência Nacional de Vigilância Sanitária. (2007). Resolução RDC no 5 de 15 de janeiro de 2007. Brasília: ANVISA. Recuperado em 16 de abril de 2020 de http://portal.anvisa.gov.br/documents/10181/2718376/RDC 052007 COMP.pdf/39e3737d -a1f5-49e6-84a1-c60f8475c1f7?version=1.0.

Bila, D. M.; Dezotti, M (2007). Desreguladores endócrinos no meio ambiente: efeitos e consequências. Química Nova, Rio de Janeiro, 30 (3), 661-666.

Fernandes, J. O. S.; Savino, G.; Amarante, A. C. G.; Souza, M, R.; Silva, G, R.; Cianciulli, M. E.; Corrêa, M. F. \& Ferrarini, M (2013). Estudo das relações entre estrutura e atividade de parabenos: uma aula prática. Quimica Nova, 36 (6), 890-893.

Freire, P (1996). Pedagogia da Autonomia: Saberes necessários à prática educativa. São Paulo: Paz e Terra.

Hoppe, A. C. \& Pais, M. C. N. (2017). Avaliação da toxicidade de Parabenos em cosméticos. Revinter, $10(3), 49-70$.

Lazzari, D. D.; Martini, J. G.; Busana, J. A. (2015). Teaching in higher education in nursing: an integrative literature review. Revista Gaúcha de Enfermagem, 36 (3), 93-101.

LEÃO, M. F. (2014). Ensinar Química por meio de alimentos: possibilidades de promover alfabetização científica na educação de jovens e adultos. Dissertação (Mestrado em Ensino), Centro Universitário UNIVATES, Lajeado, Rio Grande do Sul, Brasil.

Luca, A. G.; Santos, S. A.; Del Pino, J. C. \& Pizatto, M. C. (2018). Experimentação contextualizada e interdisciplinar: uma proposta para o ensino de ciências. Revista Insignare Scientia, 1 (2), 1-21.

Oliveira, J. R. S. (2010). A perspectiva sócio histórica de Vygotsky e suas relações com a prática da experimentação no ensino de Química. Alexandria: Revista de Educação em Ciência e Tecnologia, 3 (3), 25-45.

Oliveira, J. R. S. (2010). Contribuições e abordagens das atividades experimentais no ensino de ciências: reunindo elementos para a prática docente. Acta Scientiae, 12 (1), 139- 156.

Oliveira, M.A. \& Lima, E.M. (2008). Desenvolvimento e validação de metodologia por CLAE para determinação de metilparabeno e propilparabeno em cápsulas gelatinosas duras e transparentes. In: $48^{\circ}$ Encontro Brasileiro de Química, 2008. Recuperado em 16 de abril de 2020 de http://www.abq.org.br/cbq/2008/trabalhos/4/4-314-4797.htm.

Petruci, J. F. S.; Cardoso, A. A. \& Pereira, E. A. (2011). Desenvolvimento e validação de método analítico para determinação de benzoato, sorbato, metil e propilparabenos em produtos alimentícios utilizando a eletroforese capilar. Química Nova, 34 (7), 1177-1181.

Santos, D. M. \& Nagashima, L. A. (2017). Potencialidades das atividades experimentais no ensino de Química. Revista de Ensino de Ciências e Matemática, 8 (3), 94-108. 
Sato, M. S. (2011). Aula de laboratório no ensino superior de Química. Dissertação (Mestrado em Ciências), Universidade de São Paulo, São Carlos, São Paulo, Brasil.

Wang, L.; Zhang , X.; Wang, Y. \& Wang, W. (2006). Simultaneous determination of preservatives in soft drinks, yogurts and sauces by a novel solid-phase extraction element and thermal desorption-gas chromatography. Analytica Chimica Acta, 577(1), 62-67.

Witorsch, R. J. \& Thomas J. A. (2010). Personal care products and endocrine disruption: A critical review of the literature. Critical Reviews in Toxicology, 40, 1-30.

\section{COMO CITAR ESTE ARTIGO:}

Corrêa, T. A., Rodrigues, R. M.A., Melo, L. DE P., Costa, G. H. G.. (2020). Síntese, Identificação E Quantificação de parabenos em edulcorantes: uma abordagem contextualizada para o Ensino De Química. Holos. 36(5), 1-12.

\section{SOBRE OS AUTORES}

\section{T. A. CORRÊA}

Departamento de Ciências Exatas e da Terra, área: Química. E-mail: tais.correa@uemg.br

ORCID ID: https://orcid.org/0000-0001-9936-1479

\section{R. M.A. RODRIGUES}

Tecnologia em Alimentos. E-mail: raianearaujorodrigues97@gmail.com

ORCID ID: https://orcid.org/0000-0002-2365-5742

L. DE P. MELO

Departamento de Ciências Exatas e da Terra, área: Química. E-mail: lidervan.melo@uemg.br ORCID ID: https://orcid.org/0000-0003-1995-1247

\section{G. H. G. COSTA}

Departamento de Ciências Exatas e da Terra, área: Ciências Agrárias. E-mail: gustavo.costa@uemg.br ORCID ID: https://orcid.org/0000-0003-3723-2393

Editor(a) Responsável: Francinaide de Lima Silva Nascimento Pareceristas Ad Hoc: Arivonaldo da Silva e Marcelo Nascimento

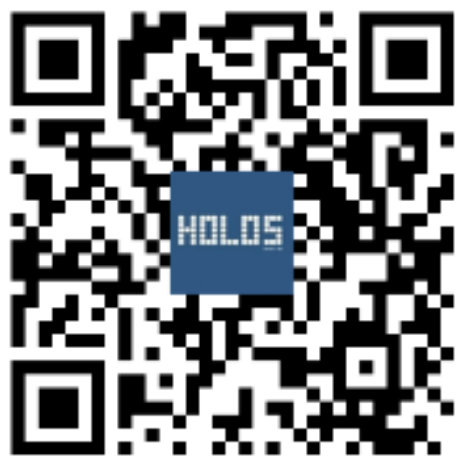

